\title{
Anne ve Çocuklarının Suda Boğulma Yöntemi ile İkili Ölümü: Olgu Sunumu
}

\section{A Drowning Case Including Mother and Her Own Children's Homicide-Suicide}

\section{Kenan Karbeyaz ${ }^{1}$,Harun Akkaya ${ }^{2}$, Yasemin Balci ${ }^{3}$}

${ }^{1} D o c ̧$. Dr. Eskişehir Adli Tip Şube Müdürlü̆ü, Eskişehir

${ }^{2} U z m$. Dr. Adli Tip Kurumu Baskanlı̆̆, İstanbul

${ }^{3}$ Muğla Sitkı Koçman Üniversitesi Tip Fakültesi Adli Tip Anabilim Dal, Muğla

*Olgu, İstanbul'da düzenlenen "22nd Congress of The International Academy of Legal Medicine IALM 2012" kongresinde poster bildirisi olarak sunulmuştur.

\section{Özet}

Suda boğulma tarzında ikili ölüm olguları ender görülen olgulardandır. Bu çalışmada, iki çocuğunu suya atarak öldürdükten sonra kendini suya atarak intihar eden anne sunulmuştur.

Olgumuzdaki anne, yirmibeş yaşında ve 6 yıllık evli olan bir kadındır. Biri 5 yaşında, diğeri 6 aylık olan çocuklarını suya atarak öldürmüş, kendisi de suya atlayarak intihar etmiştir.

Bir annenin çocuklarını suya atarak öldürmesi ve sonrasında kendisinin de suya atlayarak intihar etmesi ender görülen bir durumdur. Gerek olayın oluş şekli, gerekse anneyi intihara götüren sebeplerin tartışılması açısından olgu sunulmaya değer bulunmuştur.

Anahtar Kelimeler: Kadına yönelik şiddet, Suda boğulma, Cinayet-intihar, İkili ölüm.

\section{Abstract}

There are rare cases of homicide-suicide by drowning for both murderer and victim or victims. In this study, presenting the mother who committed suicide by throwing herself into water after murdering her two children by same method.

The mother in this case, a women 25 years who had been married for six years. She killed her two children (one of them is 5-years-old and the other is six months old) by throwing them into water, and she also committed suicide by jumping into the water.

The case of the mother who committed suicide by throwing herself into the water after murdering her two children by throwing them into water is a rare condition. The case is found worthy for discussion of the manner of deaths and the reasons leading the mother to suicide and murder her children.

Keywords: Violence against women, Drowning, Murder-Suicide, Dyatic death.

götüren sebeplerin tartışılması açısından olgu sunulmaya değer bulunmuştur.

\section{Olgu Sunumu}

2011 yılı Ekim ayında, akşam saatlerinde, karakola nehrin içinde 2 çocuk ve 1 kadın cesedinin olduğu haber verilmiştir. Yapılan incelemede cesetler hakkında aynı gün kayıp ihbarı verildiği anlaşılmıştır. Bulunan cesetlerin 25 yaşında ve 6 yıllık evli olan bir anneye ve onun biri 5 yaşında, diğeri 6 aylık olan çocuklarına ait olduğu anlaşılmıştır.

Babanın; 43 yaşında olduğu, firıncıda çalıştığı, 600 TL maaş aldığı, Güneydoğu'dan göç ettikleri, 7 yıl öncesinde resmi nikahla evlendikleri, 5 yaşındaki kız çocuğunun kendilerinin kızı olmadığ olduğundan ve bakacak durumda olmadığından kızı nüfuslarına geçirdiği, evlendikten sonra çeşitli suçlardan cezaevine girdiği, eşiyle problemlerinin olmadığı, olay günü kendisinin sabah işe gittiğini, öğleye doğru, baldızının kendisini arayarak eşini sorduğu, eşinden haber alınamadığını öğrendiği, eve gittiği, eşinin eşyalarını karıştırdığında, kol çantasının içinde bir intihar mektubu bulduğu, polise haber verdiği, akşam saatlerinde cesetlere ulaşıldığını ifade ettiği anlaşılmıştır. Ayrıca, eşinin son günlerde içine kapanık olduğunu, sorduğunda bir şey söylemediğini, kendisinden 
izinsiz hiçbir zaman dışarı çıkmadığını, ilk eşi olduğunu kimseden şikâyetçi olmadığını, daha önce birkaç kez eşine hafifçe şiddet uyguladığını ancak karakola yansımadığını ifade etmiștir.

Görgü tanıklari; Olay günü nehir kenarındaki parkta bir erkek, bir kadın ve iki çocuğun uzun süre bir bankta oturduğunu, sohbet ettiklerini, kadının oldukça üzgün olduğunu ve ağladığını, bir süre sonra erkeğin yanlarından ayrıldığını, kadının çocuklarla yalnız kaldığını, uzun süre nehrin etrafında dolaştıklarını söyledikleri anlaşılmaktadır.

Yapılan soruşturmada suda erkek cesedi olmadığ saptanmıştır. Olay günü kadının yanında olan erkek uzun süre aranmasına rağmen bulunamamıştır. Erkeğin kim olduğu, orada neler konuşulduğu sır olarak kalmıştır.

Savcılık, kadının çocukları öldürdüğü, sonra da intihar ettiğine hükmetmiş ve takipsizlik kararı vermiştir.

25 yassında kadin olgunun otopsisi; $165 \mathrm{~cm}$ boyunda $65 \mathrm{~kg}$ ağırlığında, 25 yaşlarında, buğday tenli kumral uzun saçl, kahverengi gözlü kadın cesedinde ölü katılı̆̆ının tüm vücutta oluştuğu, ölü lekelerinin sırtta açık kırmızı renkte oluştuğu görüldü. Burun ve kulak deliklerinde yosun parçaları olduğu, vücudunun tavuk derisi görünümünde olduğu görüldü. Eller ve ayak tabanlarında çamaşırcı eli görünümü saptandı. Herhangi bir travmatik lezyon izine rastlanılmadı. Baş açıldı; saçlı deri altında kanama veya ekimoz görülmedi. Kafatası kemikleri ve her iki temporal kas grubu sağlam bulundu. Kafatası açıldı. Beyin ve beyincik çıkarıldı. 1350 gr tartıldı. Yapılan kesitlerinde yer yer noktavi kanama alanları dışında özellik görülmedi. Kafa tabanı kemikleri ve dural alanlar temiz bulundu. Boyun ve göğüs açıldı; boyun cilt, cilt altında kanama, ekimoz görülmedi. Hyoit kemik, tiroit kartilaj ve boyun omurları sağlam bulundu. Özefagus ve trakeanın boş olduğu saptandı. Sternal kapak kaldırıldı. Kosta kemikleri ve sternumda kırık saptanmadi. Her iki akciğer ödemli bulundu. Sağ akciğer 550, sol akciğer 480 gr tartıldı. Kesitlerinde kanlı köpüklü ödem mayi olduğu belirlendi. Kalp çıkarıldı. 380 gr tartıldı. Kalp yüzey ve kesitlerinde patolojik özellik saptanmadı. Koronerler açık bulundu. Batın açıldı; mide pilileri sağlam bulundu. Mide içinde $150 \mathrm{cc}$ su bulundu. Barsak kesitlerinde su olduğu saptandı. Karaciğer 1330 gr tartıldı. Yüzey ve kesitlerinde patolojik özellik görülmedi. Uterus incelemesinde gebelik bulgusuna rastlanılmadı. Alınan kan örneğinde 46 $\mathrm{mg} / \mathrm{dl}$ etanol, $304 \mathrm{ng} / \mathrm{ml}$ phenobarbital saptandı. Kişinin ölümünün suda boğulmaya bağlı mekanik asfiksi sonucu meydana geldiği kanaatine varıldı.

5 yaşındaki kız çocuğunun otopsisi; $108 \mathrm{~cm}$ boyunda $25 \mathrm{~kg}$ ağırlı̆̆ında, 5 yaşlarında, buğday tenli kumral saçlı, kahverengi gözlü kız çocuğu cesedinde ölü katıllğının tüm vücutta oluştuğu, ölü lekelerinin sırtta açık kırmızı renkte oluştuğu görüldü. Her iki burun deliğinde beyaz renkte mantar köpüğü bulunduğu görüldü. Kulak etrafında yosun parçaları olduğu, cesedin tavuk derisi görünümünde olduğu görüldü. Herhangi bir travmatik lezyon izine rastlanılmadı. Baş açıldı; saçlı deri altında kanama veya ekimoz görülmedi. Kafatası kemikleri ve her iki temporal kas grubu sağlam bulundu. Kafatası açıldı. Beyin ve beyincik çıkarıldı. 1100 gr tartıldı. Yapılan kesitlerinde yer yer noktavi kanama alanları dışında özellik görülmedi. Kafa tabanı kemikleri ve dural alanlar temiz bulundu. Boyun ve göğüs açlldı; boyun cilt, cilt altında kanama, ekimoz görülmedi. Hyoit kemik, tiroit kartilaj ve boyun omurları sağlam bulundu. Özefagus ve trakeanın boş olduğu saptandı. Sternal kapak kaldırıldı. Kosta kemikleri ve sternumda kırık saptanmadı. Her iki akciğer ödemli bulundu. Sağ akciğer 200, sol akciğer 180 gr tartıldı. Kesitlerinde kanlı köpüklü ödem mayi olduğu belirlendi. Kalp çıkarıldı. 150 gr tartıldı. Kalp yüzey ve kesitlerinde patolojik özellik saptanmadı. Koronerler açık bulundu. Batın açıldı; mide pilileri sağlam bulundu. Mide içinde $50 \mathrm{cc}$ su bulundu. Barsak kesitlerinde su olduğu saptandı. Karaciğer 650 gr tartıldı. Yüzey ve kesitlerinde patolojik özellik görülmedi. Alınan kan, idrar örneklerinde alkol, uyutucu veya uyuşturucu maddeye rastlanılmadı. Kişinin ölümünün suda boğulmaya bağl1 mekanik asfiksi sonucu meydana geldiği kanaatine varıldı

6 aylık kız bebeğin otopsisi; $62 \mathrm{~cm}$ boyunda $5,5 \mathrm{~kg}$ ağırlığında, 6 aylık görünümde, buğday tenli kumral kısa saçl, ela gözlü kız bebeği cesedinde ölü katılı̆̆ının tüm vücutta oluştuğu, ölü lekelerinin sırtta açık kırmızı renkte oluştuğu görüldü. Her iki burun deliğinde beyaz renkte mantar köpüğü geldiği görüldü. Kulak etrafında yosun parçaları olduğu, cesedin tavuk derisi görünümünde olduğu görüldü. Herhangi bir travmatik lezyon izine rastlanılmadı. Baş açıldı; saçlı deri altında kanama veya ekimoz görülmedi. Kafatası kemikleri ve her iki temporal kas grubu sağlam bulundu. Ön fontanelin 3x3 $\mathrm{cm}$ açık olduğu saptandı. Kafatası açıldı. Beyin ve beyincik çıarıldı. 650 gr tartıldı. Yapılan kesitlerinde yer yer noktavi kanama alanları dışında özellik görülmedi. Kafa tabanı kemikleri ve dural alanlar temiz bulundu. Boyun ve göğüs açıldı; boyun cilt, cilt altında kanama, ekimoz görülmedi. Hyoit kemik, tiroit kartilaj ve boyun omurları sağlam bulundu. Özefagus ve trakeanın boş olduğu saptandı. Sternal kapak kaldırıldı. Kosta kemikleri ve sternumda kırık saptanmadı. Her iki akciğer ödemli bulundu. Yüzeylerinde yaygın subplevral kanama alanları görüldü. Sağ akciğer 80 , sol akciğer 70 gr tartıldı. Kesitlerinde kanlı köpüklü ödem mayi olduğu belirlendi. Kalp çıkarıldı. 50 gr tartıldı. Kalp yüzey ve kesitlerinde patolojik özellik saptanmadı. Koronerler açık, büyük damarlar normal lokalizasyonlarında bulundu. Batın açıldı; mide içinde $30 \mathrm{cc}$ su bulundu. Barsak kesitlerinde su 
olduğu saptandı. Karaciğer 250 gr tartıldı. Yüzey ve kesitlerinde patolojik özellik görülmedi. Alınan kan, idrar örneklerinde alkol, uyutucu veya uyuşturucu maddeye rastlanılmadı. Kișinin ölümünün suda boğulmaya bağlı mekanik asfiksi sonucu meydana geldiği kanaatine varıldı.

\section{Tartışma}

Cinayet-intihar tarzındaki ölümlerin çoğunda saldırgan erkek, mağdur ise kadındır. Cinayet intihar şeklindeki ölümlerde mağdurların \%90'ında ateşli silah yaralanması şeklinde tek tip lezyon saptanır. Faillerin çoğu intihar ederken ișledikleri cinayetle aynı metodu kullandığı görülmektedir (15). Doğan ve ark.(2), Konya ilinde yaptığ 1 retrospektif çalışmada tüm cinayet olaylarının \%2.9'un cinayet-intihar olayları olduğunu bildirmişlerdir. Ülkemizde bildirilen cinayetintihar olgularının çoğunluğunda cinayet metodu olarak ateşli silahlar kullanılmasına rağmen yüksekten düşme, ası, delicikesici-ezici alet, zehirleme ve strangulasyon metodları da kullanılmıștır. Bunların çoğunda failin intihar ederken cinayet metodunu kullandığı bildirilmiştir (2, 8-13).

Sunulan olguda, saldırgan kadın olup, önce kendi çocuklarını suya atarak ölümlerine sebep olmuş, sonrasında kendisi de aynı yöntemle intihar etmiștir. Bu șekilde cinayetintihar olgusuna literatürde rastlanılmamıștır. Yapılan otopsiler sonucunda üç olgunun da suda boğulmaya bağlı mekanik asfiksi nedeniyle öldüğü belirlenmiştir.

Adli tahkikat değerlendirildiğinde, olayın sırlarla dolu olduğu, ancak bu sırların çoğunun aydınlatılamadığ görülmüstür. Görgü tanıkları, olay yeri inceleme bulguları, intihar mektubu, otopsi bulguları ölümle ilgili şüpheleri giderebilir. Ancak bir anneyi çocuklarını öldürerek intihar etmeye iten sebep aydınlatılamamıștır. Olay günü kadının çocuklarını yanına alarak, intihar mektubu bırakıp evden çıkması tekrar dönmek istemediğini düşündürmektedir. Nehrin kıyısındaki parkta bir erkekle uzun süre sohbet etmesi, sonra ağlaması evlilik dıșı bir ilişkiyi düșündürmüștür. Ancak olay sonrası, bu erkek ortaya çıkmamıştır. Kadının tüm yakınları bu konuda bilgileri olmadığını ifade etmişlerdir.

Sunulan olgu, ikili ölümlerle ilgili literatürde altruistik motivasyon kavramına uymaktadır. Altruistik ikili ölümlerde, intihar etmeyi kafasına koymuş saldırgan, kendisi için halen anlamlı olan, kendi hayatından daha çok önem verdiği kișileri geride bırakmak istemez (14-16). Bunun bir örneği ruhsal rahatsızlı̆̆ olan annelerin, intihar etmeden önce çocuklarını yalnız bırakmamak için öldürmeleridir (15). Sunulan olguda benzer şeklide kadının çocuklarını geride bırakamadığı ve onları da öldürdügüü görülmektedir.

Literatürde, cinayet-intihar tarzındaki ölümlerin kadına yönelik şiddet zemininde geliştiği görülmektedir $(1,2,7,11,13)$. Bu nedenle bu tarz olaylarda; tahkikatın yalnızca adli açıdan değil, sosyal açıdan da değerlendirilmesi gerekmektedir. Olgumuzda tahkikatın sosyal açıdan fazla irdelenmediği görülmektedir. Olgumuzdaki anne, șiddete maruz kaldığı tahmin edilen, eğitimsiz bir kadındır. Çocuklarını geride bırakamadığ 1 için öldürüp, canına kıyan bu annenin öyküsünün, kadına yönelik şiddetin ülkemizdeki boyutlarını göstermesi açısından oldukça önemli olduğu düşünülmektedir.

\section{Kaynaklar}

1. Milroy CM. The epidemiology of homicide-suicide (dyadic death. Forensic Sci Int 1995;71(2):117-122.

2. Dogan KH, Demirci S, Gunaydin G, Buken B. Homicide-suicide in Konya, Turkey between 2000 and 2007. J Forensic Sci. 2010;55(1):110-5.

3. Chan CY, Beh SL, Broadburst RG. Homicide-suicide in Hong Kong, 1989-1998. Forensic Sci Int 2004;3:261-7.

4. Lecomte D, Fornes P. Homicide followed by suicide: Paris and its suburbs, 1991-1996. J Forensic Med 1998;43(4):760-4.

5. Betz P, Eisenmenger W. Comparison of wound patterns in homicide and dyadic death. Med Sci Law 1997:37(1):19-22

6. Melez IE, Avşar A, Başpınar B, Melez DO, Şahin F, Özdeş T. Simultaneous homicide-suicide: A case report of double drowning. J of Forensic Sci 2014;59(5):1432-35.

7. Marzuk PM, Tardiff K, Hirsch CS. The epidemiology of murdersuicide. JAMA 1992;267(23):3179-83

8. Hancı İH, Ege B, Ertürk S, Yemişçigil A, Karali H. İkili Ölüm: Bir olgu bildirisi. Adli Tip Dergisi 1991;7(1-2):75-7.

9. Özer E, Yıldırım A, Enginyurt Ö, Yılmaz R. Dyadic death: A case report. Gaziosmanpaşa Üniversitesi Tıp Fakültesi Dergisi 2012;(1):27-31.

10. Cantürk $\mathrm{N}$, Cantürk $\mathrm{G}$, Odabaşı $\mathrm{AB}$, İşbaşar T. Yüksekten düşme: İkili ölüm olgu sunumu. Adli Tıp Dergisi 2008;22(1):39-43.

11. Zeren C, Kiriktir E, Arslan MM. Evlilikte ikili ölüm. Dicle Tıp Dergisi 2012;39(2):306-9

12. Ak M, Gülsün M, Perdeci Z, Sütçigil L, Bozkurt A. Psikolojik otopsi: Öldürme ardından özkıyım. Anatol J Clin Investig 2009;3(1):103-5

13. Karbeyaz K, Gündüz T, Balcı Y. Yüksekten atlayarak birlikte intihar: İkili ölüm. Adli Tıp Bülteni 2007;12(3):125-9.

14. Friedman SH, Hrouda DR, Holden CE, Noffsinger SG, Resnick PJ.. Child murder committed by severely mentally ill mothers: an examination of mothers found not guilty by reason of insanity. J Forensic Sci 2005; 50:1466-71

15. Lysell H, Runeson B, Lichtenstein $\mathrm{P}$, Långström N. Risk factors for filicide and homicide: 36-year national matched cohort study. J Clin Psychiatry. 2014;75(2):127-32.

16. Hatters Friedman S, Resnick PJ. Child murder by mothers: patterns and prevention. World Psychiatry. 2007;6(3):137-41 